\title{
Correction to: Problem-based gaming via an augmented reality mobile game and a printed game in foreign language education
}

\author{
Juhee Lee ${ }^{1}$ \\ Published online: 16 December 2020 \\ (C) Springer Science+Business Media, LLC, part of Springer Nature 2020
}

\section{Correction to: Education and Information Technologies https://doi.org/10.1007/s10639-020-10391-1}

In the original publication, some of the Tables entries at the last column of Table 1 were mistakenly shifted to the 1 st column during typesetting. The correct Table is presented in this Erratum.

The online version of the original article can be found at https://doi.org/10.1007/s10639-020-10391-1

\author{
Juhee Lee \\ juheelee.carpediem@gmail.com
}

1 Department of English Education, Gyeongsang National University, 501, Jinju-daero, College of Education Building 301, \#312, Jinju 52828, South Korea 


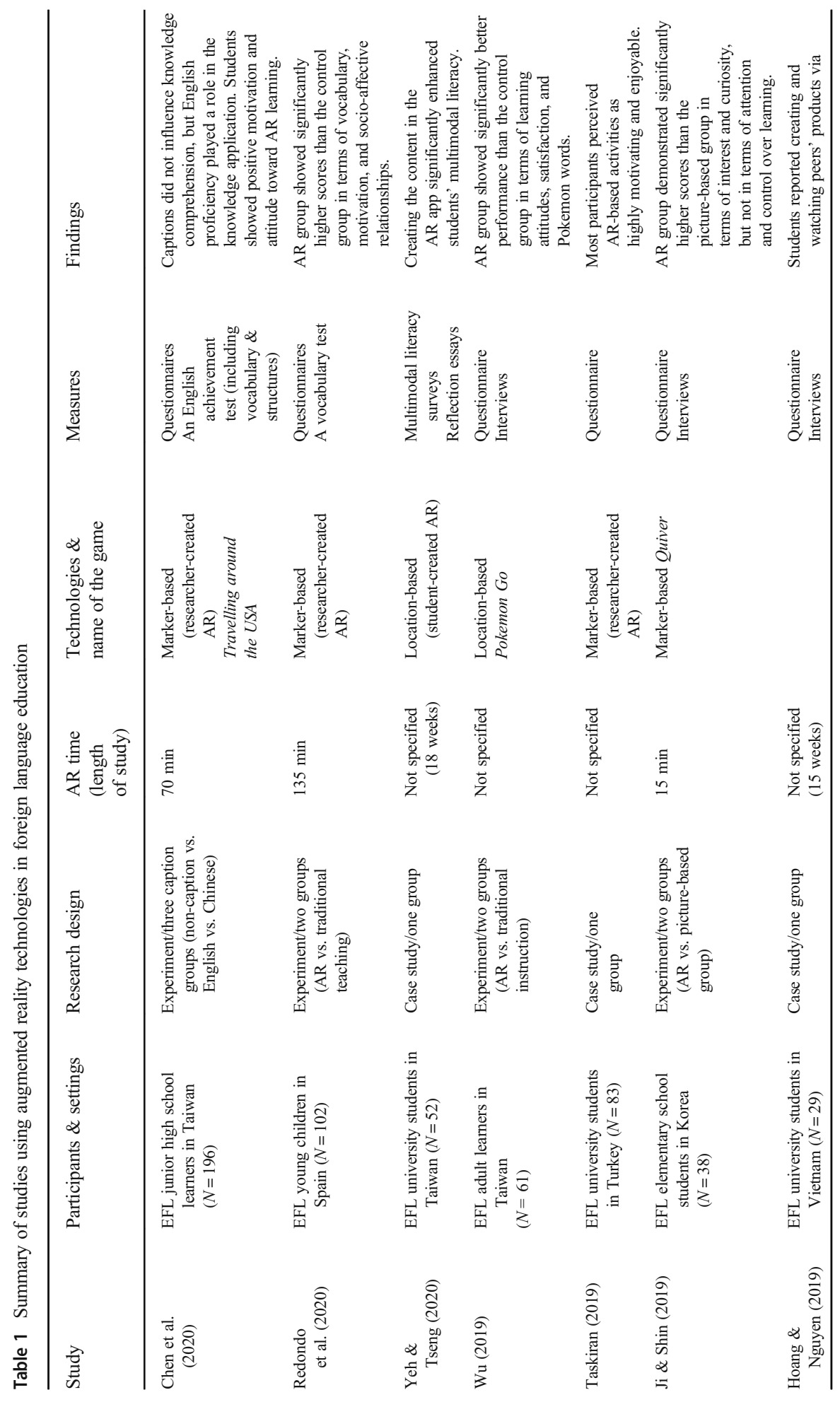




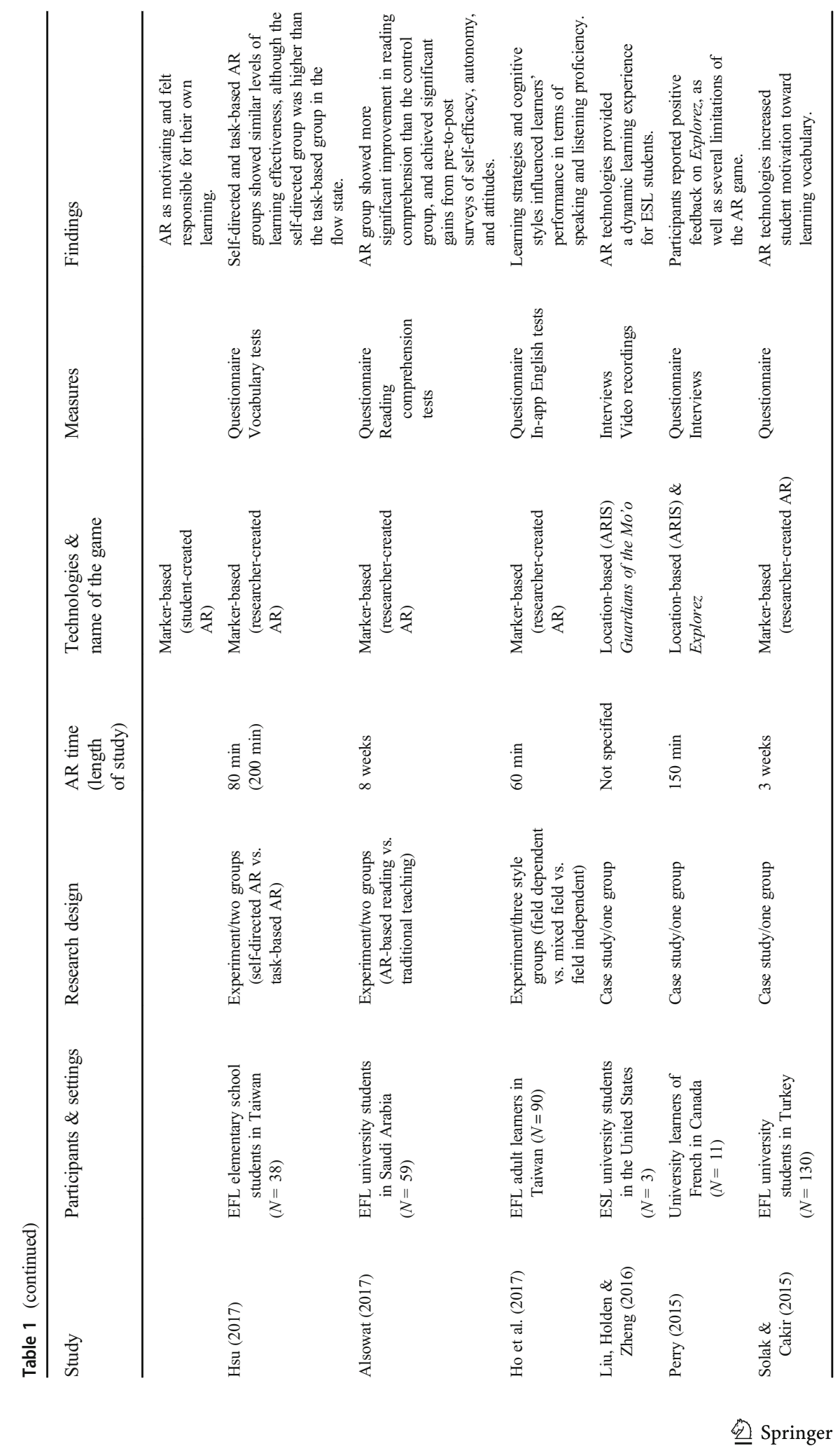




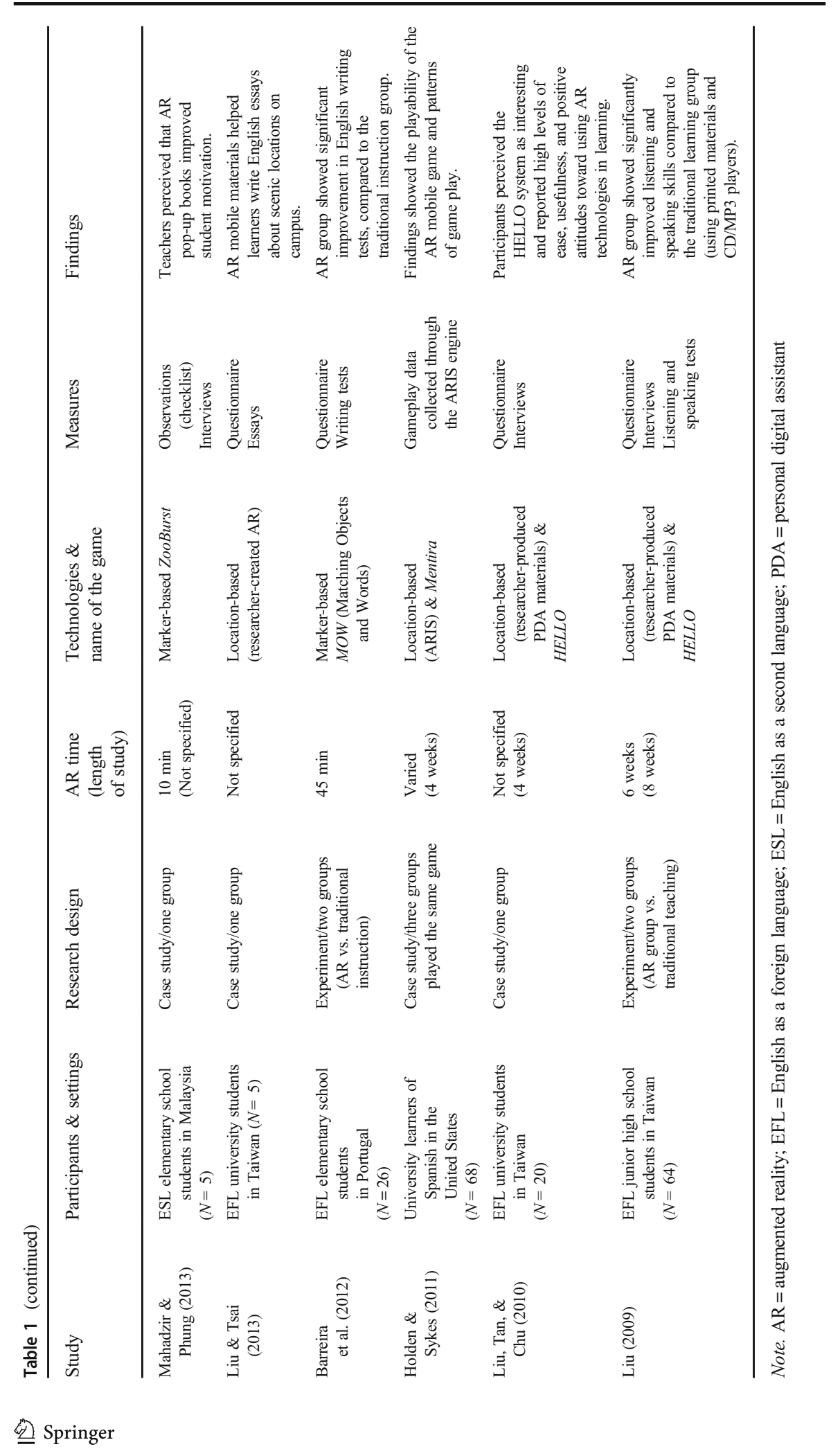


Publisher's note Springer Nature remains neutral with regard to jurisdictional claims in published maps and institutional affiliations. 